J. Asiat. Soc. Bangladesh, Sci. 46(2): 191-200, December 2020

\title{
IDENTIFICATION AND QUANTIFICATION OF SOIL PESTICIDES IN COASTAL LAKSHMIPUR DISTRICT OF BANGLADESH
}

\author{
M. AMIN UDDIN ${ }^{1}$, NASIDULABEDIN CHOWDHURY ${ }^{2}$, MD. ABDUR RAHMAN ${ }^{1}$, \\ Md. HARUNUR RASHID ${ }^{1}$, M. ALAMGIR ZAMAN CHOWDHURY ${ }^{1}$ \\ AND ZEENATH FARDOUS ${ }^{*}$ \\ ${ }^{I}$ Agrochemical and Environmental Research Division, Institute of Food and Radiation \\ Biology, Bangladesh Atomic Energy commission, Ganakbari, savar, Dhaka, Bangladesh. \\ ${ }^{2}$ Department of Biochemistry and Molecular Biology, Bangladesh National University \\ (Tejgaon College), Dhaka-1215, Bangladesh.
}

\begin{abstract}
This study was carried out to determine the presence and quantity of some selected pesticides from soil sediments collected from some ponds and canals located in the Lakshmipur district of Bangladesh. The high performance liquid chromatography (HPLC) technique was used to determine the concentration of pesticide residues. Some soil samples were found to be contaminated with carbamate (carbofuran and carbaryl) and organophosphorus (diazinon) pesticides. The concentration of carbofuran pesticide ranged from $0.303 \mu \mathrm{g} / \mathrm{kg}$ to $1.851 \mu \mathrm{g} / \mathrm{kg}$. The highest concentration of carbofuran pesticide was found in $\operatorname{SSP}_{6}(1.851 \mu \mathrm{g} / \mathrm{kg})$ and the lowest concentration was found in $\mathrm{SSP}_{9}(0.303 \mu \mathrm{g} / \mathrm{kg})$. Carbaryl pesticide was found to be present in the sediment of only one pond, the concentration being $1.047 \mu \mathrm{g} / \mathrm{kg}$. Organophosphorus (diazinon) pesticide was found in soil samples and the concentrations ranged from $0.147 \mu \mathrm{g} / \mathrm{kg}$ to 0.759 $\mu \mathrm{g} / \mathrm{kg}$, which were higher than the EEC-recommended limit of $0.1 \mu \mathrm{g} / \mathrm{kg}$.
\end{abstract}

Key words: Carbaryl, Carbofuran, Diazinon, HPLC, Soil

\section{Introduction}

Bangladesh is predominantly an agricultural country with an area of $1,47,570$ sq. km. It has only 0.31 percent of the world's total agricultural land, but 2.0 percent of the globe's total population (Hossain et al. 2015, Rasul and Thapa 2004). To feed 160 million people, different agrochemicals in the form of pesticides and fertilizers have been used in this limited agricultural land over the last few decades. This practice has led to the buildup of pesticide residues in the products, the destruction of beneficial insects, and pest resurgence. Pesticides have also been associated with environmental pollution (Rashid et al. 2015). Exposure of farm workers to pesticides has been causing various types of

*Author for correspondence: 〈zafardousbace2gmail.com>. 
cancer. These pesticides are also causing health hazards for humans such as headache, body aches, skin rashes, poor concentration, feelings of weakness, circulatory problems, dizziness, nausea, vomiting, excessive sweating, impaired vision, tremors, cramps, psychomotor dysfunction, depression, Parkinson's disease and, in severe cases, coma (Fardous et al. 2015, Hancock et al. 2008). Barring a few, humans have no remedies for the diseases caused by pesticides. Therefore, it is necessary to determine if pesticide residues are present in environmental matrices like sediments.

The World Health Organization (WHO) estimates that there are 3 million cases of pesticide poisoning each year and up to 220,000 deaths, primarily in developing countries (WHO 2001). The application of pesticides is often not very precise, and unintended exposures occur to other organisms in an area where pesticides are applied. Children and many young and developing organisms are particularly vulnerable to the harmful effects of pesticides. Even low levels of exposure during development may have adverse health effects (Sarwar 2015).

In the past, pesticides have contributed significantly to improve the yield of crops, which ensured food security for the global population. The widely cultivated high yielding variety is highly vulnerable to pests and diseases. Thus, the use of pesticides are now an inherent part of agriculture for pest control (Bagchi et al. 2008). Pests pose a serious problem because of their high reproduction potential and rapid turnover of generations. Farmers use large quantities of chemical insecticides for effective control of the pest larvae. Therefore, the aim of this study was to investigate the occurrence and amount of pesticides in the soil of a coastal region of Bangladesh.

\section{Materials and Methods}

Collection and pretreatment of samples: Twenty-five soil samples (15 soil samples from different ponds and 10 soil samples from different canals) were collected from Sadar Upazila of Lakshmipur district near the coastal area. Bags, permanent markers, spoons, boxes, etc., were used to collect soil samples. Before the collection of soil samples, bags were cleaned with detergent. Bags were marked by a permanent markers.After collection, the samples were brought to the lab at the Agrochemical and Environmental Research Division, Institute of Food and Radiation Biology, Bangladesh Atomic Energy Commission, Ganakbari, Savar, Dhaka. The samples were immediately preserved in a deep fridge $\left(-20^{\circ} \mathrm{C}\right)$ to prevent the loss of the pesticide residues. The samples were collected in August, 2016, which belongs to the rainy season in the country. Heavy rainfall washes out the topsoil and brings pesticide residues into water bodies. 
Selection of the study area: Lakshmipur is a small southeastern district of Bangladesh. Chandpur District borders it to the north, Bay of Bengal and Noakhali district to the south, Noakhali District to the east, and Meghna river to the west. About $47.51 \%$ people are engaged in agriculture for their occupation in Lakshmipur district. The main crops in this district are paddy, wheat, potato, pulse, sugarcane, etc. But paddy is the most cultivated crop. Our study area is Lakshmipur Sadar Upazila, which is located at $22.95^{\circ} \mathrm{N}$ and $90.82^{\circ} \mathrm{E}$ (Fig. 1). In the Sadar Upazila, paddy and vegetables, especially cucumber are cultivated the most. 'Basudin', an organophosphorus pesticide, is used by the farmers which contains 'Diazinon'. Another brand of pesticide, which contains mostly 'Carbaryl' and 'Carbofuran' of 'Carbamate' is also used by the farmers. Most of the paddy fields are located near ponds, and most of the time, the drainage water of those paddy fields flows to the nearest ponds. Some ponds are lying, and their banks are too low to prevent the incoming water from the nearby paddy fields in rainy seasons. The vegetable fields are located near the canals and the drainage water flows to the canals.

Sample processing in laboratory: Fifty (50) gm soil sample was taken in a conical flask $(250 \mathrm{ml})$ and $100 \mathrm{~mL}$ of solvent (a mixture of hexane and acetone at 1:1) was added to the conical flask. The conical flask was then shaken for 6-7 hrs using a mechanical shaker and the contents were allowed to settle down. Finally, the extract (hexane: acetone mixture) was collected from the conical flask. Similarly, the extract mixture was collected two more times with $25 \mathrm{ml}$ solvent by hand shaking for $5 \mathrm{~min}$. Ten gm of anhydrous sodium sulphate $\mathrm{Na}_{2} \mathrm{SO}_{4}$ was added to the combined extract and the contents were allowed to settle. The solvent was then decanted and subsequently evaporated by a rotary vacuum evaporator to dryness. Two (2) $\mathrm{mL}$ of HPLC-grade acetonitrile was added in three portions and the sample extracts were collected into a vial for clean-up. The extract was subjected to clean-up using florisil column chromatography, where necessary. The top $1.5 \mathrm{~cm}$ of the florisil column was packed with anhydrous $\mathrm{Na}_{2} \mathrm{SO}_{4}$. Elution was done with $2 \%$ diethyl ether in hexane $(5 \mathrm{ml} / \mathrm{min})$. The eluate was concentrated in a rotary vacuum evaporator and transferred to glass-stoppered test tubes. The solvent was completely removed under mild nitrogen flow. The evaporated sample was dissolved in acetonitrile and the volume was made up to $1 \mathrm{ml}$ in a volumetric flask for analysis in high performance liquid chromatography (HPLC) (Uddin et al. 2016, 2018).

Identification and quantification procedures: The analysis was conducted by an HPLC (Shimadzu, Japan) LC-10ADvp, equipped with an SPD-M 10 Avp attached to a photodiode array detector (Shimadzu SPD-M 10 Avp, 200-800 nm). A C18 Reverse Phase Alltech $(250 \times 4.6 \mathrm{~mm}, 5 \mu \mathrm{m})$ was used as the analytical column, and the column temperature was maintained at $30^{\circ} \mathrm{C}$. Acetonitrile in distilled water (70:30) was used as 
the mobile phase at a flow rate of $1.0 \mathrm{ml} / \mathrm{min}$. Prior to HPLC analysis, the samples were filtered through $0.45 \mu \mathrm{m}$ nylon (Alltech Associates, IL, USA) syringe filters. The chromatograms were obtained following manual injection $(20 \mu \mathrm{l})$ of both standard and sample solution. The suspected pesticides were identified based on the retention times of the respective standard pesticide preparation.

For the preparation of the calibration curve, equal volumes of several different concentrations of standard solutions were injected into the HPLC machine. Tentative identification of the suspected pesticides was carried out in relation to the retention time (RT) of the pure analytical standards. Quantification was performed according to the calibration method described by Bhattacharjee et al., (2012). For this purpose, the injection of equal volumes of differently concentrated standard solutions into HPLC prepared calibration curve for each pesticide. To determine the residual levels of pesticides, the following equation was used:

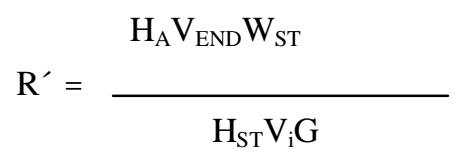

Where,

$$
\begin{aligned}
& \mathrm{R}^{\prime}=\mathrm{mg} / \mathrm{l} \text { for water and } \mathrm{mg} / \mathrm{Kg} \text { for soil } \\
& \mathrm{G}=\text { Sample weight }(1 \text { or } \mathrm{Kg}) \\
& \mathrm{V}_{\mathrm{END}}=\text { Terminal volume of the sample solution }(\mathrm{mL}) \\
& \mathrm{V}_{\mathrm{i}}=\text { Portion of volume } \mathrm{V}_{\mathrm{END}} \text { injected into HPLC }(\mu \mathrm{L}) \text { column } \\
& \mathrm{W}_{\mathrm{ST}}=\text { Amount of standard pesticides injected with standard solvent }(\mu \mathrm{g}) \\
& \mathrm{H}_{\mathrm{A}}=\text { Peak area obtained from } \mathrm{V}_{\mathrm{i}}\left(\mathrm{mm}^{2}\right) \\
& \mathrm{H}_{\mathrm{ST}}=\text { Peak area obtained from } \mathrm{W}_{\mathrm{ST}}\left(\mathrm{mm}^{2}\right)
\end{aligned}
$$

Extraction efficiency/recovery: The validation of the analytical method was performed according to the European Commission (EC) guidelines in terms of the accuracy, precision, and limit of quantification (LOQ) (DG SANCO, 2010). Accuracy was calculated by analyzing the samples of known concentration $(n=3)$ and comparing the estimated values with the actual values. Within our experimental limit, the mean recovery for accuracy should be within 70-120\%. For accuracy experiments, soil (50 g) was utilized as a matrix after homogenization and the addition of an appropriate amount of pesticide standards at two different fortification levels (0.02 and $0.20 \mathrm{ppm})$. Control samples were processed along with spiked ones. Both sample and standard preparation 
were allowed to stand for one hour to permit equilibration. Equilibration was followed by the extraction and clean up process, as described above. Percentage recovery was calculated by the following equation:

Percentage recovery $=[\mathrm{CE} / \mathrm{CM} \times 100]$

Where CE is the experimental concentration determined from the calibration curve and $\mathrm{CM}$ is the spiked concentration. The precision was estimated by monitoring the repeated $(n=6)$ peak response and expressed by the relative standard deviation (RSD). The acceptance criterion for precision is RSD $\leq 20 \%$. Analytical procedures employed are found to be satisfactory and average recoveries between $72 \%$ and $95 \%$ were obtained for Carbofuran, Carbaryl and Diazinon pesticides from the soil samples (the fortifications were made in the range $0.02-0.2 \mathrm{ppm}$ level), indicating the suitability of the methodology. The LOQ and LOD were evaluated as signal-to-noise ratios $(\mathrm{S} / \mathrm{N})$ of 10:1 and $3: 1$, respectively. In the present study, the LOD and LOQ were $0.01 \mathrm{mg} / \mathrm{kg}$ and 0.05 $\mathrm{mg} / \mathrm{kg}$, respectively.

\section{Results and Discussion}

Toxic pesticides are widely used in agricultural lands for prevention of valuable crop losses by pests. Pesticides improve yield as well as the quality of the product. However, pesticides pose serious health risks to farmers exposed to pesticides when they mix and apply for pesticides or work in the pesticides-treated fields. People in general also get exposed to the pesticide residues in food and drinking water. In this investigation, Sadar Upazila of Lakshmipur district was taken as the study area. The outer part of Sadar Upazila belongs to "lotic" ecosystem because of the presence of the Meghna River, while the inner part of it belongs to "lentic" ecosystem because of the presence of many manmade ponds and some natural water sources such as pools, canals, and lakes. Most of the man-made ponds and canals are in close proximity to these agricultural fields. Therefore, when soils of agricultural fields are contaminated by pesticides, the nearby water bodies are also contaminated. Pesticide residues find their way to these water bodies through surface run-off during precipitation and after irrigation.

Tables 1 and 2 show the average concentration of pesticide residues in soil samples collected from different ponds and canals of Sadar Upazilla, Lakshmipur. The retention time and area for carbofuran, carbaryl, and diazinon are presented in Tables 3-5. Fifteen soil samples were collected from ponds and ten soil samples were collected from canals of the area. Six soil samples representing ponds and canals were found to be 
contaminated with residues of carbofuran. Carbofuran was present in $\mathrm{SSP}_{6}, \mathrm{SSP}_{7}, \mathrm{SSP}_{9}$ and $\mathrm{SSC}_{6}, \mathrm{SSC}_{7}, \mathrm{SSC}_{10}$. The concentration of carbofuran ranged from 0.303 to 1.851 $\mu \mathrm{g} / \mathrm{kg}$. The highest concentration $(1.851 \mu \mathrm{g} / \mathrm{kg})$ was found in $\mathrm{SSP}_{6}$ and the lowest concentration $(0.303 \mu \mathrm{g} / \mathrm{kg})$ was in $\mathrm{SSP}_{9}$. Carbaryl residue was observed only in the $\mathrm{SSP}_{8}$ sample with a concentration of $1.047 \mu \mathrm{g} / \mathrm{kg}$. Table 1 and Table 2 also show the soil samples that were found to be contaminated with diazinon. Four soil samples, namely $\mathrm{SSC}_{9}, \mathrm{SSP}_{1}, \mathrm{SSP}_{13}$, and $\mathrm{SSP}_{15}$, were contaminated with diazinon. The highest concentration $(0.759 \mu \mathrm{g} / \mathrm{kg})$ was found in $\mathrm{SSP}_{15}$, and the lowest concentration $(0.147$ $\mu \mathrm{g} / \mathrm{kg}$ ) was found in $\mathrm{SSP}_{1}$. Data of the present study indicate the contamination of soil with an organophosphate. Organophosphorus pesticides have been widely used in Bangladesh since 1990 because organochlorine insecticides were banned due to their persistence as well as acute toxicity in the environment (Chowdhury et al. 2012). The use of organophosphorus and carbamate pesticides such as chlorpyrifos, diazinon, malathion, carbofuran, and carbaryl has greatly increased because of their less detrimental effects on the environment (Chowdhury et al. 2012). Many studies reported very high concentration of organophosphate and carbamate residues in the soil and water of Bangladesh (Bhattacharjee et al. 2012, Chowdhury et al. 2012, Chowdhury et al. 2013, Shammi et al. 2014). In our previous study, carbofuran was detected at a higher concentration of 3.21 $\mu \mathrm{g} / \mathrm{kg}$, carbaryl at $2.52 \mu \mathrm{g} / \mathrm{kg}$ and diazinon at $0.235 \mu \mathrm{g} / \mathrm{kg}$ in samples collected from vegetable and paddy field in the coastal district Feni of Bangladesh (Uddin et al. 2018). Carbofuran and carbaryl concentrations in the present study were lower than those of the previous study. On the other hand, diazinon concentration was found to be at a higher level than our previous study. However, the contamination level of organophosphorus and carbamate was relatively low compared to the IAEA/FAO/Codex Alimentarius Guideline values.

Carbamate pesticides were observed in soils of both pond and canal near the paddy and vegetable fields of Sadar Upazila. Among the carbamate and organophosphate pesticides, diazinon, carbofuran and carbaryl are frequently used in Bangladesh. When the soil samples were collected, farmers said, they had been using diazinon, carbofuran, and carbaryl. Therefore, the study was carried out to determine the presence and quantity of diazinon, carbofuran, and carbaryl pesticides. A better understanding about degradation of these pesticides in soil and the factors affecting the degradation process may help in the judicious application of these pesticides and the consequent mitigation of environmental pollution (Chowdhury et al., 2002). There is no data on pesticide pollution in the studied area. Therefore, this study provides some baseline data to help future investigation on pesticide pollution in the area. 


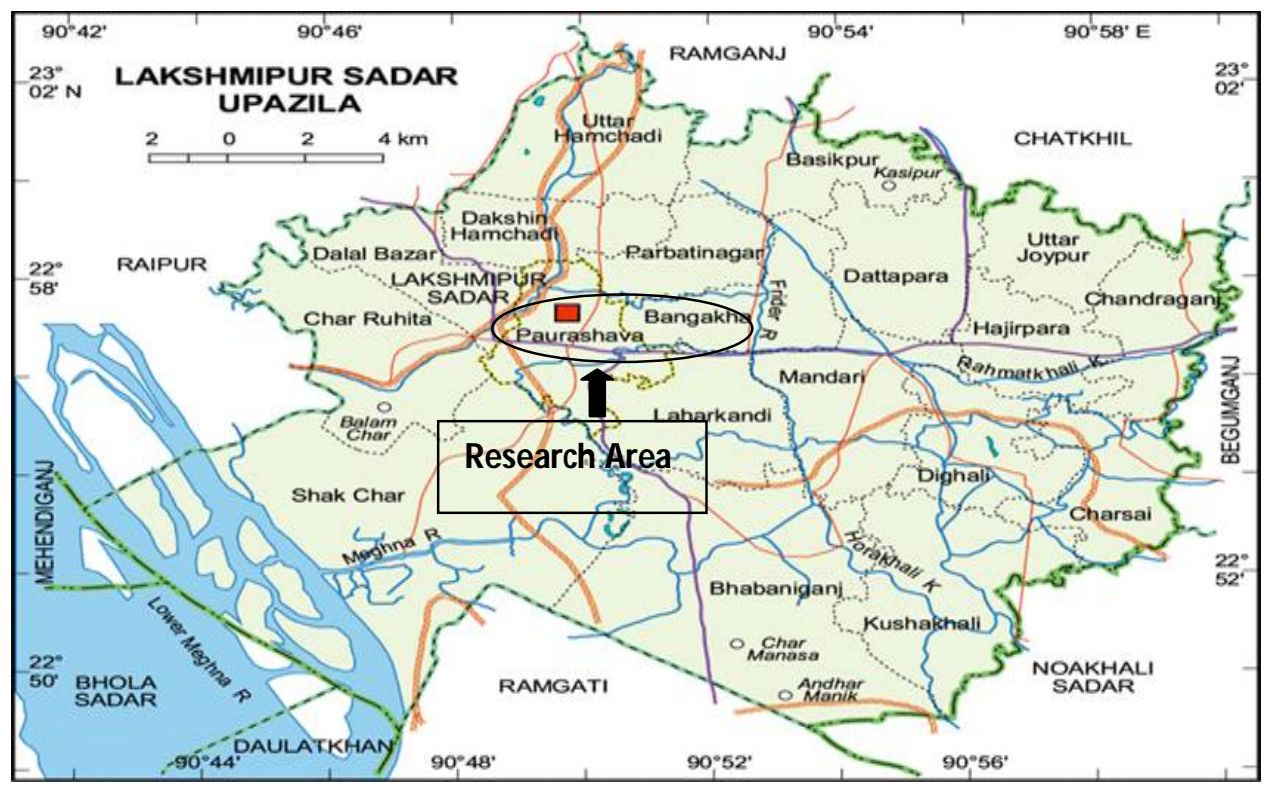

Fig. 1. Map of Sadar Upazila showing the sampling locations.

Table 1. The average concentration of pesticide residues in soil samples which were collected from different ponds of Sadar Upazila, Lakshmipur.

\begin{tabular}{lllll}
\hline $\begin{array}{l}\text { Sample } \\
\mathrm{ID}\end{array}$ & Sampling location & $\begin{array}{l}\text { Carbofuran } \\
(\mu \mathrm{g} / \mathrm{kg})\end{array}$ & $\begin{array}{l}\text { Carbaryl } \\
(\mu \mathrm{g} / \mathrm{kg})\end{array}$ & $\begin{array}{l}\text { Diazinon } \\
(\mu \mathrm{g} / \mathrm{kg})\end{array}$ \\
\hline $\mathrm{SSP}_{1}$ & Kachari Bari pond & $\mathrm{BDL}$ & $\mathrm{BDL}$ & 0.147 \\
$\mathrm{SSP}_{2}$ & Lakshmipur Markaz Mosque Pond & $\mathrm{BDL}$ & $\mathrm{BDL}$ & $\mathrm{BDL}$ \\
$\mathrm{SSP}_{3}$ & Monir Uddin Patwary Bari Pond & $\mathrm{BDL}$ & $\mathrm{BDL}$ & $\mathrm{BDL}$ \\
$\mathrm{SSP}_{4}$ & Tomehar Bazar Pond & $\mathrm{BDL}$ & $\mathrm{BDL}$ & $\mathrm{BDL}$ \\
$\mathrm{SSP}_{5}$ & Tomehar Bazar Mosque Pond & $\mathrm{BDL}$ & $\mathrm{BDL}$ & $\mathrm{BDL}$ \\
$\mathrm{SSP}_{6}$ & West Shayedpur Mosque Pond & 1.851 & $\mathrm{BDL}$ & $\mathrm{BDL}$ \\
$\mathrm{SSP}_{7}$ & Pearapur Bazar Pond & 0.167 & $\mathrm{BDL}$ & $\mathrm{BDL}$ \\
$\mathrm{SSP}_{8}$ & Vobanigonj Bazar Pond & $\mathrm{BDL}$ & 1.047 & $\mathrm{BDL}$ \\
$\mathrm{SSP}_{9}$ & Mia Bari Big Pond & 0.303 & $\mathrm{BDL}$ & $\mathrm{BDL}$ \\
$\mathrm{SSP}_{10}$ & Chourasta Bazar Pond & $\mathrm{BDL}$ & $\mathrm{BDL}$ & $\mathrm{BDL}$ \\
$\mathrm{SSP}_{11}$ & Jakshin Road Point Pond & $\mathrm{BDL}$ & $\mathrm{BDL}$ & $\mathrm{BDL}$ \\
$\mathrm{SSP}_{12}$ & Vobachat Bazar Pond & $\mathrm{BDL}$ & $\mathrm{BDL}$ & $\mathrm{BDL}$ \\
$\mathrm{SSP}_{13}$ & Torabgonj Borobari Pond & $\mathrm{BDL}$ & $\mathrm{BDL}$ & 0.395 \\
$\mathrm{SSP}_{14}$ & Torabgonj Bazar Pond & $\mathrm{BDL}$ & $\mathrm{BDL}$ & $\mathrm{BDL}$ \\
$\mathrm{SSP}_{15}$ & Koroitola Bazar Pond & $\mathrm{BDL}$ & $\mathrm{BDL}$ & 0.759 \\
\hline
\end{tabular}

Note: SSP $=$ Soil Sample of Pond, BDL = Below Detection Limit and $\mu \mathrm{g} / \mathrm{kg}=$ microgram per kilogram. 
Table 2. The average concentration of pesticides residues in soil samples which were collected from different canals of Sadar Upazila, Lakshmipur.

\begin{tabular}{lllll}
\hline $\begin{array}{l}\text { Sample } \\
\mathrm{ID}\end{array}$ & Sample Sources & $\begin{array}{l}\text { Carbofuran } \\
(\mu \mathrm{g} / \mathrm{kg})\end{array}$ & $\begin{array}{l}\text { Carbaryl } \\
(\mu \mathrm{g} / \mathrm{kg})\end{array}$ & $\begin{array}{l}\text { Diazinon } \\
(\mu \mathrm{g} / \mathrm{kg})\end{array}$ \\
\hline $\mathrm{SSC}_{1}$ & Meghna River & $\mathrm{BDL}$ & $\mathrm{BDL}$ & $\mathrm{BDL}$ \\
$\mathrm{SSC}_{2}$ & Wapdar Khal West Point & $\mathrm{BDL}$ & $\mathrm{BDL}$ & $\mathrm{BDL}$ \\
$\mathrm{SSC}_{3}$ & Wapdar Khal Middle Point near Voberhat & $\mathrm{BDL}$ & $\mathrm{BDL}$ & $\mathrm{BDL}$ \\
$\mathrm{SSC}_{4}$ & Wapdar Khal North Point near Torabgonj & $\mathrm{BDL}$ & $\mathrm{BDL}$ & $\mathrm{BDL}$ \\
$\mathrm{SSC}_{5}$ & Wapdar Khal near Lakshmipur Bas Terminal & $\mathrm{BDL}$ & $\mathrm{BDL}$ & $\mathrm{BDL}$ \\
$\mathrm{SSC}_{6}$ & Rahmat Khali Khal near Meghna River & 1.732 & $\mathrm{BDL}$ & $\mathrm{BDL}$ \\
$\mathrm{SSC}_{7}$ & Rahmat Khali Khal near West Point & 1.657 & $\mathrm{BDL}$ & $\mathrm{BDL}$ \\
$\mathrm{SSC}_{8}$ & Rahmat Khali Khal near Cucumber field & $\mathrm{BDL}$ & $\mathrm{BDL}$ & $\mathrm{BDL}$ \\
& (Koroitola) & & & \\
$\mathrm{SSC}_{9}$ & Rahmat Khali Khal north Point & $\mathrm{BDL}$ & $\mathrm{BDL}$ & 0.222 \\
$\mathrm{SSC}_{10}$ & Lakshmipur Khal near Ramgong Highway & 1.069 & $\mathrm{BDL}$ & $\mathrm{BDL}$ \\
& Road & & & \\
\hline
\end{tabular}

Note: $\mathrm{SSC}=$ Soil Sample of Canal, BDL $=$ Below Detection Limit and $\mu \mathrm{g} / \mathrm{kg}=$ microgram per kilogram.

Table 3. Sample Analysis Report of Carbofuran.

\begin{tabular}{llll}
\hline Sample No & Retention Time & Area & Concentration $(\mu \mathrm{g} / \mathrm{kg})$ \\
\hline $\mathrm{SSC}_{6}$ & 3.334 & 332133 & 1.732 \\
$\mathrm{SSC}_{7}$ & 3.351 & 317882 & 1.657 \\
$\mathrm{SSC}_{10}$ & 3.367 & 205149 & 1.069 \\
$\mathrm{SSP}_{6}$ & 3.357 & 355086 & 1.851 \\
$\mathrm{SSP}_{7}$ & 3.304 & 32159 & 0.167 \\
$\mathrm{SSP}_{9}$ & 3.344 & 58121 & 0.303 \\
\hline
\end{tabular}

Table 4. Sample Analysis Report of Carbaryl.

\begin{tabular}{llll}
\hline Sample No & Retention Time & Area & Concentration $(\mu \mathrm{g} / \mathrm{kg})$ \\
\hline $\mathrm{SSP}_{8}$ & 3.549 & 604601 & 1.047 \\
\hline
\end{tabular}

Table 5. Sample Analysis Report of Diazinon.

\begin{tabular}{llll}
\hline Sample No & Retention Time & Area & Concentration $(\mu \mathrm{g} / \mathrm{kg})$ \\
\hline $\mathrm{SSC}_{9}$ & 3.329 & 76875 & 0.222 \\
$\mathrm{SSP}_{1}$ & 3.296 & 51027 & 0.147 \\
$\mathrm{SSP}_{13}$ & 3.296 & 136634 & 0.395 \\
$\mathrm{SSP}_{15}$ & 3.284 & 262320 & 0.759 \\
\hline
\end{tabular}

[SSC=Soil Sample of Canal; SSP= Soil Sample of Pond $]$. 
The wide use of pesticides in Bangladesh causes major health and environmental problems. It is necessary to learn more about the problems caused by exposure to pesticides with respect to safety, health and the environment. A guideline should be provided for farmers on pesticide usage, safety instructions, preparation, application and disposal, and washing of equipment. As a result, the health hazards of pesticides may be reduced to a great extent. The environment and ecosystems will also be protected from the scourge of pesticide pollution. The present study has implications considering the health hazard associated with these pesticides. A further exhaustive investigation needs to be carried out to assess the status of these pesticides in foodstuff and in the food chain.

\section{Acknowledgements}

The authors would like to thank the Agrochemical and Environmental Research Division authorities, Bangladesh Atomic Energy Commission, for providing laboratory facilities to carry out these experimental studies. Also, thanks to Md. Alamgir Kabir, Abdul Hamid, and Gopal Mojumder for helping in the sample extraction process.

\section{References}

Bagchi S., A.K. Azad, M. Alamgir, Z. Chowdhury, M. Amin Uddin, Sharif M. Al-Reza and A. Rahman. 2008. Quantitative Analysis of Pesticide Residues in some Pond water samples of Bangladesh. Asian J. Water, Environ. Pollut. 6(4): 27-30.

Bhattacharjee, S., Fakhruddin, A.N., Chowdhury, M.A.Z., Rahman, M.A., Alam, M.K. 2012. Monitoring of selected pesticides residue levels in water samples of paddy fields and removal of cypermethrinand chlorpyrifos residues from waterusing rice bran. Bull. Environ. Contam. Toxicol. 89(2): 348-353.

Chowdhury, M.A.Z., Islam, M.N., Moniruzzaman, M., Gan, S.H. and Alam, M.K. 2013. Organochlorine insecticide residues are found in surface, irrigated water samples from several districts in Bangladesh. Bull. Environ. Contam. Toxicol. 90(2): 149-154.

Chowdhury, M.A.Z., Jahan, S.A., Islam, M.N., Moniruzzaman, M., Alam, M.K., Zaman, M.A., Karim, N., Gan, S.H., 2012. Occurrence of organophosphorus and carbamate pesticide residues in surface water samples from the Rangpur district of Bangladesh. Bull. Environ. Contam. Toxicol. 89(1): 202-207.

Chowdhury, N., M. A. Malek, S. M. Ullah and M. M. Rahman., 2002. Fate of $\left[{ }^{14} \mathrm{C}\right]$-carbofuran pesticide studied in a sandy loam soil in laboratory conditions. J. Asiat. Soc. Bangladesh, Sci. 28(1): 19-26.

DG SANCO, 2010. Method validation and quality control procedures for pesticide residues analysis in food and feed, Document SANCO/10684/2009, 2010, http://www.crlpesticides.eu/library/docs/allcrl/Aqc Guidance Sanco 2009 10684.pdf. 
Fardous Z., Rashid M.H., Chowdhury M.A.Z, Alam M.K., Md Rahman A, Uddin M.A. and Bari M.L., 2015. Assessment of heavy metals, minerals and pesticides in different branded drinking bottled water of Bangladesh and their impact on human health. Asia-Pacific J. Food Safety and Security 1(1): 27-41.

Hancock, D.B., E.R. Martin, G.M. Mayhew, J.M. Stajich, R. Jewett, M.A. Stacy, B.L. Scott, J.M. Vance and W.K. Scott. 2008. Pesticide exposure and risk of Parkinson's disease: A familybased case-control study. BMC Neurology 8(6): 1-12.

Hossain S, M. Alamgir Zaman Chowdhury, Md. Mashihul Alam, Nazrul Islam, Md. Harunur Rashid and Israt Jahan. 2015. Determination of Pesticide Residues in Brinjal, Cucumber and Tomato using Gas Chromatography and Mass Spectrophotometry (GC-MS). Adv. Biochem. Biotechnol. 1(1): 1-16.

Rashid,M.H., D. Sikdar, I. Jahan and S. Mojumder. 2015. Characterization of Total Cellulase and endo- $\beta$-1,4-glucanase and their Application in Biofuels Production as well as Protection of Crops from Damaging by Insects. Canadian Chem. Trans. 3(3): 275-284.

Rasul G and G.B. Thapa. 2004. Sustainability of ecological and conventional agricultural systems in Bangladesh: An assessment based on environmental, economic and social perspectives. Agricult. System 79(3): 327-351.

Sarwar M. 2015. The Dangers of Pesticides Associated with Public Health and Preventing of the Risks. Intl. J. Bioinformatics and Biomedical Engin. 1(2): 130-136.

Shammi, M., M.A.Z. Chowdhury, N . Ferdous, M.A. Rahman, M.N. Islam, A.K.M. A. Sultana and M.K. Alam. 2014. Pesticide contamination of rice field agro-ecosystem: hazard perspectives of surface water quality and aquatic livesfrom Gazipur District, Bangladesh. $J U$ Environ. Bull. 3: 11-22.

Uddin M.A, M.H. Rahman , M. Nesha, M.A.Z. Choudhury, Z. Fardous and M.A. Rahman. 2018. Studies Pesticide Residues in Soils of Some Selected Spots of Coastal Region of Bangladesh. Nuclear Sci. Appl. 27(1\&2): 13-17.

Uddin M.A,M. Alamgir Z. Chowdhury, Z. Fardous and M. Hasanuzzaman. 2016. Quantification of Pesticide Residues in some Soils of Narshindi Area 2016. Bangladesh J. Sci. Res. 29(1): 85-88.

World Health Organization. 2001. International code of conduct on the distribution and use of pesticides by Food and Agricultural Organization of the United Nations, Rome.

(Revised copy received on 29.11.2020) 